\title{
İş Güvenliği Kültürünün Un Sanayi Sektöründe Çalışanların Güvenlik Performansına Etkisi (Konya İli Örneği)
}

\author{
Sirer Albayrak ${ }^{1}$, Hasan Tuna ${ }^{2 *}$ \\ ${ }^{1}$ Ağrı İbrahim Çeçen Üniversitesi, MYO, Makine ve Metal Teknolojileri Bölümü, Ağrı, Türkiye, (0000-0002-0953-571X), sireralbayrak@gmail.com \\ 2*Gümüşhane Üniversitesi, Kelkit Aydın Doğan MYO, Elektrik ve Enerji Bölümü, Gümüşhane, Türkiye, (0000-0003-3194-7216), hasan.tuna@gumushane.edu.tr
} (International Conference on Design, Research and Development (RDCONF) 2021 - 15-18 December 2021)

(DOI: 10.31590/ejosat.1040092)

ATIF/REFERENCE: Albayrak, S., Tuna, H. (2021). İş Güvenliği Kültürünün Un Sanayi Sektöründe Çalışanların Güvenlik Performansına Etkisi (Konya İli Örneği). Avrupa Bilim ve Teknoloji Dergisi, (32), 160-166.

\begin{abstract}
$\ddot{O} \mathbf{z}$
İş kazaları çalışanların çalışma hayatlarında karşılaştıkları en önemli sorunlardan biridir. İnsanlığın çalışma hayatı boyunca olabilecek kazaları engelleme ve çalışanlara sağlıklı bir ortam oluşturmak amacıyla birçok mevzuat ve kurumsal düzenlemeler yapılmıştır. Buna rağmen, işyerlerinde hâlâ birçok kaza meydana gelmektedir. Son zamanlarda iş kazalarının önlenmesi konusunda güvenlik kültürü kavramının üzerinde önemle durulmaktadır. İşyerlerinde güvenlik kültürünün oluşturulmasında işs sağlı̆̆ ve güvenliği önemli bir rol oynamaktadır. Bu çalışmada un sektöründe çalışanların güvenlik kültürü algılarının güvenlik performanslarına etkisi incelenmiştir. Araştırmanın örneklemini basit örnekleme yöntemiyle belirlenen Konya ilinde un sektöründe faaliyet gösteren 2 farklı firmada çalışan 164 kişi oluş̧urmuştur. Veri toplama aracı olarak Dursun (2011) tarafindan Türkçeye uyarlanan 9 farklı ölçek kullanılmıştır. Araştırmada verilerin analizinde IBM SPSS 25 paket programı kullanılmışıı. Araştırmanın sonucunda raporlama kültürü ve güvenlik farkındalığ 1 değişkenlerinin güvenlik uyumu üzerinde önemli bir yordayıcı olduğu, raporlama kültürü, kadercilik, çalışanların katılımı, güvenlik farkındalığı ve yöneticilerin davranışları değişkenlerinin ise güvenlik katılımı üzerinde önemli bir yordayıcı olduğu tespit edilmiştir.
\end{abstract}

Anahtar Kelimeler: Un Sanayi, Güvenlik Kültürü, Güvenlik Performansı, İş Güvenliği.

\section{The Effect of Occupational Safety Culture on the Safety Performance of Employees in the Flour Industry Sector (Example of Konya Province)}

\begin{abstract}
Occupational accidents are one of the most important problems faced by employees in their working lives. Many legislations and institutional arrangements have been made in order to prevent accidents that may occur during the working life of humanity and to create a healthy environment for employees. Despite this, many accidents still occur in the workplace. Recently, the concept of safety culture has been emphasized in the prevention of occupational accidents. Occupational health and safety play an important role in creating the concept of a positive safety culture in a workplace. In this study, the effect of safety culture perceptions of employees in the flour industry on safety performance was examined. The sample of the research consists of 164 people working in 2 different companies operating in the flour sector in Konya, which was determined by a simple sampling method. As a data collection tool, 9 different scales adapted to Turkish by Dursun (2011) were used. IBM SPSS 25 package program was used in the analysis of the data in the research. As a result of the research, it was determined that the variables of reporting culture and security awareness were an important predictor of safety compliance, while the variables of reporting culture, fatalism, employee participation, security awareness and managers' behaviors were found to be an important predictor of safety engagement.
\end{abstract}

Keywords: Flour Industry, Safety Culture, Safety Performance, Work Safety.

* Sorumlu Yazar: hasan.tuna@gumushane.edu.tr 


\section{Giriş}

İş kazaları ve meslek hastalıklarının iş hayatında çok ciddi bir problem olarak gündeme gelmesi, dünyada olduğu gibi Türkiye'de de iş sağlığı ve güvenliği (ISG) kavramının öne çıkmasında öncülük etmiştir (İşçi Sağlığı ve İş Güvenliği Raporu, 2015). Sosyal Güvenlik Kurumunun 2020 yılı iş kazası istatistiklerine göre Türkiye'de 384262 iş kazası meydana gelmiş, 1231 çalışan iş kazasına bağlı sebeplerden dolayı hayatını kaybetmiştir. Gıda ürünlerinin imalatında ise 21945 iş kazası meydana gelmiş, 20 çalışan iş kazasına bağlı sebeplerden dolayı hayatını kaybetmiştir (Sosyal Güvenlik Kurumu, 2020). $\mathrm{Bu}$ veriler Türkiye için İSG'nin göz ardı edilmeyecek kadar önemli olduğunu göstermektedir.

2012 yılında yayımlanan 6331 Sayılı İSG Kanunu ile birlikte Türkiye'deki tüm işyerlerinde çalışan sayısı ve işyerinde yapılan iş fark etmeksizin ISG hizmetlerinin yerine getirilmesi zorunlu olmuştur (Resmi Gazete, 28339). Bu kanun çalışanların sağlık ve güvenliğini sağlamak için işverene bazı yükümlülükler getirmiştir. Bu yükümlülükler Kanunun 4. Maddesinde "işveren mesleki risklerin önlenmesi, eğitim ve bilgi verilmesi dâhil her türlü tedbirin alınması, organizasyonun yapılması, gerekli araç ve gereçlerin sağlanması, sağlık ve güvenlik tedbirlerinin değişen şartlara uygun hale getirilmesi ve mevcut durumun iyileştirilmesi için gerekli çalışmaları yapar. Risk değerlendirmesini yapar veya yaptırır. Ayrıca iş sağlığı ve güvenliği tedbirlerine uyulup uyulmadığını izler, denetler ve denetleme sonucunda uygunsuzluk varsa bu uygunsuzlukların giderilmesini sağlar." hükmü yer almaktadır (Resmi Gazete, 28512). Ayrıca bu kanun, işyerinde İSG hizmetlerinin yerine getirilmesinde tam zamanlı veya yarı zamanlı iş güvenliği uzmanı istihdamını zorunlu kılmıştır (Resmi Gazete, 28339).

İş kazalarını önlenmeye yönelik, geçmiş yıllardan günümüze kadar birçok yasal ve kurumsal anlamda düzenlemeler yapılmasına rağmen iş kazası istatistikleri, yapılan çalışmaların çok fazla başarıya ulaşamadığını göstermektedir. Buradan hareketle iş kazalarını sadece teknik bir mesele olarak görmeyip aynı zamanda insan faktörünün de dikkate alınması gerekmektedir (Aytaç, 2011). İş kazalarını önleme veya azaltma amacıyla alınan ilk tedbirler, çoğunlukla teknik konuların çözülmesi ve fiziksel tehlikelerin ortadan kaldırılması konularını kapsamaktadır. Ancak sorunu çözmede bu teknik önlemlerin yeterli olmadığ 1 anlaşılınca, araştırmacılar insan faktörünü incelemeye başlamışlardır. $\mathrm{Bu}$ incelemelere göre, iş kazalarının yaklaşık \%90'ına kişilerin güvensiz davranışları sebep olmaktadır (Tomas vd., 1999). Bu durumun iş kazalarının önlenmesi konusunda güvenlik kültürü kavramının önemini ortaya koyduğunu göstermektedir.

Güvenlik kültürü, “değerlerin, algıların, tutumların ve örgüt üyeleri tarafından paylaşılan örgüt güvenliği ile ilgili davranış kalıplarının kümesi olmakla birlikte, organizasyonu her kademesinde çalışanların maruz kaldığı mesleki risklerin azaltılmasına odaklanan, kaza ve meslek hastalıklarının önlenmesi ile yüksek bir seviyede ilgilenen uygulamalar ve prosedürler bütünü” olarak tanımlanmıştır (Muniz vd., 2007). Başka bir tanıma göre güvenlik kültürü "kaliteyi veya örgütün hedeflerini geliştirmek amacıyla lider, yöneticiler ve çalışanların sürekli devam eden faaliyetleri neticesinde ortaya çıkan temel değerleri, oluşan normları ve davranışları" ifade etmektedir (American Nurses Association, 2016). Pozitif güvenlik kültürüne sahip kuruluşlar, karşılıklı güvene dayanan iletişim, güvenliğin öneminin ortak algısı ve önleyici tedbirlerin etkinliğine olan güven ile karakterize edildiği vurgulanmaktadır (Cox ve Cheyne, 2000; Cooper, 2000). İşyerlerinde ISG faaliyetlerinde çalışanların iş kazası ile meslek hastalığını önlemede iş güvenliği boyutunu kültürel olarak işveren ve çalışan ile beraber yerleşik hale getirmenin temel adımı güvenlik kültürüdür. Çalışan, işveren ve işletme bu kültürün birer öznesidir. Birbirleri ile etkileşimli ve sistematik bir uyum ile bağlantı kurulursa her bir özne yapması gerekeni sağlıklı ve güvenlikli olarak yürütülebilir (Turan Yıldız, 2019).

Güvenlik kültürü ile ilgili hem teorik hem de uygulama düzeyinde birçok çalışma yapılmıştır. Yapılan çalışmalar güvenli ve sağlıklı bir çalışma ortamı oluşturulmasında güvenlik kültürünün önemli bir faktör olduğunu göstermiştir (Akdeniz, 2018; Dursun, 2011; Fung vd., 2005; Kao, 2008; Lee, 1998; Martin, 2007; Smith ve Wadsworth, 2009; Zohar, 2010). Güvenlik kültürü kavramı, kaza oluşumlarını ve iş yaralanmalarını azaltma üzerindeki olumlu etkileri nedeniyle uzmanlar tarafindan kabul edilmektedir (Zohar, 2010). Literatürde güvenlik kültürünün çalışanların güvenlik performansı üzerine etkisini gösteren çalışmalarda mevcuttur (Clarke, 1999; Çelik, 2014; Dursun, 2011; Goh vd., 2012; Molenaar vd., 2009).

Gıda ürünleri imalatı iş kazası ve buna bağlı ölümlerin sıklıkla meydana gelebildiği bir sektördür (Akkoyun, 2013). Sosyal Güvenlik Kurumunun 2020 yılı iş kazası istatistikleri incelendiğinde, iş kazalarının yaklaşık \%6'lık kısmı gıda ürünlerinin imalatında meydana gelmiştir (Sosyal Güvenlik Kurumu, 2020). Bu durumun Türkiye'de gida sektörü için İSG'nin göz ardı edilmeyecek kadar önemli olduğunu göstermektedir. Gıda sektöründe Parlak ve diğerleri (2020) tarafından yapılan araştırmada; çalışanların eğitim sürekliliğinin sağlanması ve denetimlerin arttırılmasılyla iş kazalarının minimize edileceği vurgulanmıştır. Türkiye genelinde gıda sektörünün dinamik oluşu ve istihdam imkânı payının yüksekliği, üretimin devamlılığının gerekliliğini de ortaya koymaktadır. Bu nedenle sektörde yaşanabilecek iş kazalarının gerçekleşmesini engellemek, dolaylı olarak sektördeki istihdamın sürekliliğini ve işverenin pazardaki yerine katkı sağlayacaktır (Oral ve Ünal, 2020). Kim ve Park (2021) tarafindan Güney Kore'de imalat sanayilerinde yaşanan iş kazalarının performans üzerindeki etkileri araştırılmıştır. Yapılan çalışma sonucunda meydana gelen iş kazalarının sadece çalışanlara ciddi fiziksel ve/veya zihinsel zarar vermekle kalmadığı, kazaya uğrayanlara ödenen tazminat maliyetleri dışında doğrudan üretim sisteminin durmasına ve kurumsal imajın düşmesine de neden olduğu tespit edilmiştir. Kısaca, İSG kültürünü yürütülen işin tüm evrelerine entegre edilmesi dolaylı olarak üretim devamlılığının sağlanmasına ve çalışma veriminin artmasına neden olacaktır (Dursun, 2013; Hasanhanoğlu, 2020).

$\mathrm{Bu}$ çalışmada, un fabrikasında çalışanların güvenlik kültürü algılarının güvenlik performansları üzerindeki etkisinin incelenmek için aşağıdaki sorulara yanıt aranmıştır.

1. Un sanayi sektöründe çalışanların güvenlik kültürü algılarının güvenlik uyumu üzerinde etkisi var mıdır?

2. Un sanayi sektöründe çalışanların güvenlik kültürü algılarının güvenlik katılımı üzerinde etkisi var mıdır? 


\section{Materyal ve Metot}

\subsection{Araştırmanın Şekli}

Un sanayi sektöründe çalışanların güvenlik kültürü algılarının güvenlik performansı üzerindeki etkisini incelemek için anket tekniği kullanılmıştır. Veriler nicel araştırma yöntemlerinden ilişkisel tarama modeli ile toplanmıştır. $\mathrm{Bu}$ model, dikkatli bir biçimde seçilmiş örneklem grubunun kendi kendine bildirim ölçütlerinin kullanımını içeren nicel bir yaklaşımdır (Converse, 1987). Karasar (2009: 81), ilişkisel tarama modelini "iki veya daha fazla sayıdaki değişken arasındaki değişimin varlığını ve/veya derecesini belirlemeyi hedefleyen araştırma modeli” olarak tanımlamıştır.

\subsection{Araştırmanın Evreni ve Örneklemi}

Araştırmanın evrenini; Konya ilinde bulunan 2 farklı un fabrikasındaki çalışanlar, örneklemini ise basit örnekleme yöntemiyle saptanan 164 çalışan oluşturmuştur. Çalışmamızda güvenlik kültürünün çalışanların güvenlik performansı üzerine etkisini belirlemek için Konya ilinde kısmi zamanlı iş güvenliği uzmanı ve işyeri hekimi bulunan orta ölçekli un fabrikalarındaki çalışanlar çalışma grubunu oluşturmuştur.

\subsection{Araştırma Verilerinin Toplanması ve Analizi}

Çalışanların güvenlik kültürünü tespit etmek için farklı alt boyutları olan farklı ölçekler literatürde kullanılmaktadır. Çalışmamızda hem geçerliliği ve güvenirliliği yüksek hem de sanayi sektörüne uygun olmasından dolayı Dursun (2011) tarafından Türkçe'ye uyarlanan dokuz farklı ölçek kullanılmıştır.

Yönetim Bağlılığı: Un sektöründe yöneticilerin çalışanların güvenliğine bağlılığını değerlendirmek için 8 madde ve 2 alt boyuttan (4 madde yöneticilerin tutumları ve 4 madde yöneticilerin davranışları) oluşan Muniz ve diğerleri (2007) tarafından geliştirilen ölçek kullanılmıştır.

Güvenlik Önceliği: Un sektöründe çalışanların iş güvenliğinin taşıdığı önem düzeyini nasıl algıladıklarını değerlendirmek için 4 maddeden oluşan Cox ve Cheyne (2000) tarafından geliştirilen ölçek kullanılmıştır.

Güvenlik İletişimi: Un sektöründe çalışanların yönetim ile arasındaki iletişimi güvenlik açısından değerlendirmek için 5 maddeden oluşan Neal ve diğerleri (2000) tarafından geliştirilen ölçek kullanılmıştır.

Güvenlik Eğitimi: Un sektöründe verilen güvenlik eğitimi ile ilgili çalışanların algılarını değerlendirmek için 4 maddeden oluşan Neal ve diğerleri (2000) tarafından geliştirilen ölçek kullanılmıştır.

Güvenlik Farkındalığı ve Yetkinlik: Un sektöründe çalışanların güvenlik farkındalığını değerlendirmek için 5 maddeden oluşan Lin ve diğerleri (2008) tarafından geliştirilen ölçek kullanılmıştır.

Çalışanların Katılımı: Un sektöründe çalışanların güvenlik çalışmalarına katılımını değerlendirmek için 4 maddeden oluşan Muniz ve diğerleri (2007) tarafından geliştirilen ölçek kullanılmıştır.

Kadercilik: Un sektöründe çalışanların iş kazalarıyla ilgili kaderci inanışlarını değerlendirmek için Rundmo ve Hale (1999) tarafından geliştirilen ve Havold ve Nesset (2009) çalışmasından alınan 6 maddeden oluşan ölçek kullanılmıştır.
Raporlama Kültürü: Un sektöründe çalışanların raporlama algılarını değerlendirmek için Havold ve Nesset (2009) tarafindan geliştirilen 5 maddeden oluşan ölçek kullanılmıştır.

Güvenli Davranış Ölçeği: Çalışanların güvenli davranışlarını değerlendirmek için 6 madde ve 2 alt boyuttan (3 madde güvenlik uyumu ve 3 madde güvenlik katılımı) oluşan Neal ve diğerleri (2000) tarafindan geliştirilen ölçek kullanılmıştır.

Veriler Konya ilindeki fabrikalarda görevli iş güvenliği uzmanları ve araştırmacı tarafından uygulanan anket formuyla toplanmıştır. Elde edilen 175 anket formundan 11'i eksik veri içerdiği için kapsam dışında bırakılmış, 164 anket formu analiz edilmiştir.

Araştırmada toplanan verilerin analiz edilmesi için IBM SPSS 25 paket programı kullanılmıştır. Çarpıklık ve basıklık katsayılarının $\pm 1, \pm 1.5$ ve \pm 2 sınırları içinde 0 'a yakın olması normal dağılımın varlığına kanıt olarak değerlendirilmektedir (Hair vd., 2013; Tabachnick ve Fidell, 2013; George ve Mallery, 2010). Güvenlik kültürü boyutlarının çarpıklık ve basıklık katsayılarının \pm 1 aralığında olması ölçeklerin normal dağıldığını göstermektedir. Verilerin değerlendirilmesinde korelasyon ve regresyon analizi yapılmıştır. Araştırmada güvenilirliği ölçmek amacıyla Cronbach Alfa katsayısına bakılmıştır. Ölçme aracının iç tutarlılık (Cronbach Alfa) katsayısının .70'den yüksek olması ölçeğin güvenirliği açısından yeterli olduğu ileri sürülmektedir (Büyüköztürk, 2010; Fraenkel ve Wallen, 2006; Nunnally, 1978; Şencan, 2005). Güvenlik kültürü ölçeğinin Cronbach Alfa katsayısı .884 güvenli davranış ölçeğinin Cronbach Alfa katsayısı da .721 olarak tespit edilmiştir. Ölçeklerin Cronbach Alfa katsayıları .70'den büyük olduğu için güvenilir olduğu söylenebilir.

\subsection{Araştırmanın Etik Yönü}

01/07/2021 tarih ve 2021/5 karar sayılı Gümüşhane Üniversitesi Bilimsel Araştırma ve Yayın Etiği Kurulundan "İ̧ş Güvenliği Kültürünün Un Sanayi Sektöründe Çalışanların Güvenlik Performansına Etkisi (Konya İli Örneği)" araştırmanın yapılabilmesi için etik kurul onayı alınmıştır.

\section{Araştırma Sonuçları ve Tartışma}

Un sektöründe çalışanların güvenlik kültürü düzeylerinin, çalışanların güvenli davranışlarına etkisinin olup olmadığı incelenmiştir. $\mathrm{Bu}$ kapsamda, elde edilen bulgular benzer çalışmalarla karşılaştırılarak yorumlanmıştır.

Güvenlik kültürü değişkenlerinin çalışanların güvenli davranışları (güvenlik katılımı ve güvenlik uyumu) arasındaki ilişkinin tespit edilmesi amacıyla yürütülen korelasyon analizi sonuçları Tablo 1'de gösterilmiştir.

Kadercilik değişkeninin güvenlik uyumu ile anlamlı bir ilişkisinin olmadığı, güvenlik katılımı ile zayıf ve negatif yönlü anlamlı bir ilişki içinde olduğu saptanmıştır. Çalışanların katılımı değişkeninin güvenlik uyumu ile anlamlı bir ilişkisinin olmadığı, güvenlik katılımı ile orta ve pozitif yönlü anlamlı bir ilişki içinde olduğu tespit edilmiştir. Diğer güvenlik kültürü değişkenlerinin hem güvenlik katılımı hem de güvenlik uyumu değişkenleri ile pozitif yönlü anlamlı bir ilişki içinde olduğu belirlenmiştir. Güvenlik katılımı değişkeninin en güçlü ilişsi içinde olduğu değişken yönetici davranışları $(\mathrm{r}=.48 ; \mathrm{p}<.01)$, 
güvenlik uyumu değişkenin ise güvenlik farkındalığıdır ( $\mathrm{r}=.48$; $\mathrm{p}<.01)$ (Tablo 1).

Un sektöründeki çalışanların güvenlik uyumunun çalışanların katılımı ve kadercilik dışındaki diğer tüm güvenlik kültürü değişkenleri ile pozitif yönlü anlamlı bir ilişkisinin olduğu, güvenlik katılımının ise kadercilik değişkeni ile negatif yönlü diğer güvenlik kültürü değişkenleri ile pozitif yönlü anlamlı bir ilişki saptanmıștır. Yılmaz ve Yılmaz (2011) tarafından inşaat sektöründeki çalışanlar üzerine yapılan çalışmada da çalışanların güvenli davranışlarının güvenlik kültürü değişkenleri ile pozitif yönlü anlamlı bir ilişki tespit edilmiştir. Dursun (2011) tarafından imalat sektöründeki çalışanlar üzerine yapılan çalışmada çalışanların güvenli davranışlarının kadercilik dışındaki diğer tüm güvenlik kültürü değişkenleri ile pozitif yönlü anlamlı bir ilişki saptanmıştır. Can ve Hüseyinli (2017) tarafindan yapılan diğer çalışmada da çalışanların güvenlik kültürü algılarının, güvenli davranış eğilimleri üzerinde pozitif yönlü anlamlı bir ilişkiye sahip olduğu görülmüştür.

Tablo1. Güvenlik kültürü değişkenleri ile güvenli davranış arasındaki korelasyon analizi sonuçları

\begin{tabular}{|c|c|c|c|c|c|c|c|c|c|c|}
\hline & 1 & 2 & 3 & 4 & 5 & 6 & 7 & 8 & 9 & 10 \\
\hline \multicolumn{11}{|l|}{ 1. Yöneticilerin Tutumları } \\
\hline 2. Yöneticilerin Davranışları & $.69 * *$ & & & & & & & & & \\
\hline 3. Güvenlik Önceliği & $.66^{* *}$ & $.58 * *$ & & & & & & & & \\
\hline 4. Güvenlik İletişimi & $.58 * *$ & $.52 * *$ & $.63 * *$ & & & & & & & \\
\hline 5. Güvenlik Eğitimi & $.55 * *$ & $.57 * *$ & $.47 * *$ & $.64 * *$ & & & & & & \\
\hline 6. Güvenlik Farkındalığı & $.38 * *$ & $.44 * *$ & $.36 * *$ & $.24 * *$ & $.31 * *$ & & & & & \\
\hline 7. Çalışanların Katılımı & $.39 * *$ & $.40 * *$ & $.40 * *$ & $.53 * *$ & $.52 * *$ & .15 & & & & \\
\hline 8. Kadercilik & -.07 & -.04 & -.02 & -.02 & -.00 & $-.18 *$ & $.32 * *$ & & & \\
\hline 9. Raporlama Kültürü & $.37 * *$ & $.34 * *$ & $.28 * *$ & $.26 * *$ & $.24 * *$ & $.40 * *$ & $.26 * *$ & .06 & & \\
\hline 10. Güvenlik Uyumu & $.20 * *$ & $.28 * *$ & $.17 *$ & $.20 *$ & $.22 * *$ & $.48 * *$ & .15 & -.09 & $.44 * *$ & \\
\hline 11. Güvenlik Katılımı & $.39 * *$ & $.48 * *$ & $.40 * *$ & $.40 * *$ & $.38 * *$ & $.46 * *$ & $.32 * *$ & $-.18 *$ & $.45 * *$ & $.45^{* *}$ \\
\hline
\end{tabular}

Un sektöründeki çalışanların güvenlik kültürü algılarının güvenlik performansı üzerinde etkili olduğu saptanmıştır. Literatürdeki çalışmalar incelendiğinde farklı sektörlerde yapılan araştırmalar güvenlik kültürü boyutlarının güvenlik performansı üzerinde etkili olduğu tespit edilmiştir (Can ve Hüseyinli, 2017; Choudhry vd., 2007; Çelik, 2014; Dursun 2011; Dursun, 2013;
Goh vd., 2012; Molenaar, 2009; Özkan ve Arpat, 2015; Y1lmaz ve Yilmaz, 2016).

Güvenlik kültürü değişkenlerinin güvenlik uyumu üzerindeki etkisini incelemek amaciyla yürütülen çoklu regresyon analizi sonuçları Tablo 2'de gösterilmiştir.

Tablo 2. Güvenlik kültürü değişkenlerinin güvenlik uyumuna etkisi çoklu regresyon analizi sonuçları

\begin{tabular}{lccccc}
\hline & $\mathrm{B}$ & $\mathrm{S} . \mathrm{H}$. & $\beta$ & $\mathrm{t}$ & $\mathrm{p}$ \\
\hline Sabit & 1.35 & .38 & & 3.52 & .001 \\
Yöneticilerin Tutumları & -.12 & .10 & -.13 & -1.22 & .226 \\
Yöneticilerin Davranışları & .07 & .10 & .08 & .81 & .418 \\
Güvenlik Önceliği & -.06 & .10 & -.07 & -.67 & .503 \\
Güvenlik İletişimi & .06 & .10 & .07 & .69 & .490 \\
Güvenlik Eğitimi & .04 & .10 & .04 & .38 & .705 \\
Güvenlik Farkındalı̆̆1 & .41 & .10 & .35 & 4.31 & .000 \\
Çalışanların Katılımı & .02 & .02 & .02 & .21 & .835 \\
Kadercilik & -.05 & -.06 & -.06 & -.82 & .411 \\
Raporlama Kültürü & .29 & .31 & .31 & 4.10 & .000 \\
\hline $\mathrm{R}=.566, \mathrm{R}^{2}=.320, \mathrm{~F}_{(9-154)}=8.050, \mathrm{p}=.000$ & & & & \\
\hline
\end{tabular}

Oluşturulan regresyon modelinin anlamlı olduğu tespit edilmiştir $\quad(\mathrm{F}(9-154)=8.050, \quad \mathrm{p}<.001) . \quad$ Güvenlik kültürü değişkenlerinin güvenlik uyumuna ilişsin varyansın \%32'sini açıklamaktadır $\quad\left(\mathrm{R}^{2}=.320\right)$. Regresyon katsayılarının anlamlılığına ilişkin sonuçlar incelendiğinde ise raporlama kültürü $(\beta=.31, \mathrm{t}=4.10, \mathrm{p}<.001)$ ve güvenlik farkındalığı $(\beta=.35$, $\mathrm{t}=4.31, \quad \mathrm{p}<.001)$ değişkenlerinin güvenlik uyumu üzerinde önemli (anlamlı) bir yordayıcı olduğu görülmektedir. Diğer güvenlik kültürü değişkenleri ise önemli bir etkiye sahip değildir (Tablo 2).

Güvenlik kültürü değişkenlerinin güvenlik uyumu üzerine etkileri incelendiğinde raporlama kültürü ve güvenlik 
farkındalığı değişkenlerinin güvenlik uyumu üzerinde önemli bir yordayıcı olduğu tespit edilmiştir. Buradan hareketle çalışanların çalışma ortamındaki tehlike ve risklere karşı farkındalığının arttırılması ve güçlü bir raporlama sistemi oluşturularak raporlama kültürünün geliştirilmesi güvenliğe uyma davranışını olumlu etkilemektedir. Dursun (2011) tarafindan yapilan çalışmada güvenlik farkındalığı ve raporlama kültürü değişkenlerinin yanı sıra çalışanların katılımı ve kadercilik değişkenlerinin de güvenlik uyumu üzerinde anlamlı bir etkiye sahip olduğu tespit edilmiştir. Yılmaz ve Y1lmaz (2016) tarafından yapılan çalışmada da güvenlik farkındalığı, raporlama kültürü, güvenlik önceliği, güvenlik iletişimi ve çalışanların katılımı değişkenlerinin güvenlik uyumu üzerinde anlamlı bir etkiye sahip olduğu saptanmıştır. Can ve Hüseyinli (2017) ise yönetimin tutum ve davranışları, çalışanların ilgisi, kişisel öncelikleri ve güvenlik ihtiyaçları değişkenlerinin güvenlik uyumu üzerinde anlamlı bir etkiye sahip olduğunu tespit etmişlerdir.

Güvenlik kültürü değişkenlerinin güvenlik katılımı üzerindeki etkisini incelemek amacıyla yürütülen çoklu regresyon analizi sonuçları Tablo 3’te gösterilmiştir.

Tablo 3. Güvenlik kültürü değişkenlerinin güvenlik katılımına etkisi çoklu regresyon analizi sonuçları

\begin{tabular}{lccccc}
\hline & $\mathrm{B}$ & $\mathrm{S} . \mathrm{H}$. & $\beta$ & $\mathrm{t}$ & $\mathrm{p}$ \\
\hline Sabit & .65 & .42 & & 1.56 & .121 \\
Yöneticilerin Tutumları & -.14 & .11 & -.12 & -1.25 & .212 \\
Yöneticilerin Davranışları & .22 & .10 & .20 & 2.19 & .030 \\
Güvenlik Önceliği & .10 & .10 & .09 & 1.01 & .314 \\
Güvenlik İletişimi & .08 & .10 & .08 & .85 & .395 \\
Güvenlik Eğitimi & .04 & .10 & .03 & .36 & .721 \\
Güvenlik Farkındalığı & .25 & .10 & .18 & 2.45 & .015 \\
Çalışanların Katılımı & .18 & .09 & .16 & 1.99 & .048 \\
Kadercilik & -.20 & .06 & -.21 & -3.11 & .002 \\
Raporlama Kültürü & .29 & .08 & .27 & 3.84 & .000 \\
\hline R=.653, $\mathrm{R}^{2}=.426, \mathrm{~F}_{(9-154)}=12.711, \mathrm{p}=.000$ & & & & \\
\hline
\end{tabular}

Olușturulan regresyon modelinin anlamlı olduğu tespit edilmiştir $\quad(\mathrm{F}(9-154)=12.711, \quad \mathrm{p}<.001) . \quad$ Güvenlik kültürü değişkenlerinin güvenlik katılımına ilişkin varyansın \%43’ünü açıklamaktadır $\quad\left(\mathrm{R}^{2}=.426\right)$. Regresyon katsayılarının anlamlılığına ilişkin sonuçlar incelendiğinde ise raporlama kültürü $(\beta=.27, \mathrm{t}=3.84, \mathrm{p}<.001)$, kadercilik $(\beta=-.21, \mathrm{t}=-3.11$, $\mathrm{p}<.01)$, çalışanların katılımı $(\beta=.16, \mathrm{t}=1.99, \mathrm{p}<.05)$, güvenlik farkındalığı $(\beta=.18, \mathrm{t}=2.45, \mathrm{p}<.05)$ ve yöneticilerin davranışları $(\beta=.20, \quad \mathrm{t}=2.19, \quad \mathrm{p}<.05)$ değişkenlerinin güvenlik katılımı üzerinde önemli (anlamlı) bir yordayıcı olduğu görülmektedir. Diğer güvenlik kültürü değişkenleri ise önemli bir etkiye sahip değildir (Tablo 3).

Güvenlik kültürü değişkenlerinin güvenlik katılımı üzerine etkileri incelendiğinde raporlama kültürü, kadercilik, çalışanların katılımı, güvenlik farkındalığı ve yöneticilerin davranışları değişkenlerinin güvenlik katılımı üzerinde önemli bir yordayıcı olduğu tespit edilmiştir. Dursun (2011) tarafından yapılan çalışmada yöneticilerin davranışları değişkeninin dışındaki güvenlik farkındalığı, çalışanların katılımı, raporlama kültürü ve kadercilik değişkenlerinin güvenlik katılımı üzerinde anlamlı bir etkiye sahip olduğu saptanmıştır. Yılmaz ve Yılmaz (2016) tarafından yapılan çalışmada ise sadece güvenlik farkındalı̆̆ı, raporlama kültürü ve güvenlik iletişimi değişkenlerinin güvenlik katılımı üzerinde anlamlı bir etkiye sahip olduğu tespit edilmiştir. Can ve Hüseyinli (2017) ise yönetimin tutum ve davranışları, çalışanların ilgisi, kişisel öncelikleri ve güvenlik ihtiyaçları değişkenlerinin güvenlik katılımı üzerinde anlamlı bir etkiye sahip olduğunu saptamışlardır. Neal ve diğerleri (2000) hastanedeki çalışanlar üzerine yaptıkları çalışma ile Griffin ve Neal (2000) imalat ve maden sektöründe çalışanlar üzerine yaptıkları çalışmada da güvenlik ikliminin güvenli davranışı doğrudan etkilediği belirlenmiştir.

\section{Sonuç}

Un sektöründe çalışanların güvenlik kültürü algılarının güvenli davranışları üzerindeki etkisi incelenmiştir. Güvenlik kültürü ve güvenlik performansı arasında anlamlı bir ilişki tespit edilmiştir. Güvenlik kültürü değişkenlerinin güvenlik performansı üzerine etkileri incelendiğinde raporlama kültürü ve güvenlik farkındalığı değişkenlerinin güvenlik uyumu üzerinde önemli bir yordayıcı olduğu, raporlama kültürü, kadercilik, çalışanların katılımı, güvenlik farkındalığı ve yöneticilerin davranışları değişkenlerinin ise güvenlik katılımı üzerinde önemli bir yordayıcı olduğu tespit edilmiştir.

Un sektöründe sağlıklı ve güvenli bir çalışma ortamının oluşturulmasında güvenlik kültürü büyük önem arz etmektedir. Un sektöründeki iş kazalarının nedenlerinden biri istenilen seviyede güvenlik kültürünün olmamasıdır. Eğitim düzeyi yüksek çalışanların istihdam edilmesi ve eğitim faaliyetlerinin arttırılması, yönetimin tutum ve davranışlarının geliştirilmesi, kadercilik anlayışının ortadan kaldırılması, farkındalığı ve yetkinliği artırıcı tedbirlerin alınması, çalışanların güvenliğe aktif katılımının sağlanması, etkili iletișiminin kurulması, güçlü bir raporlama sistemi oluşturularak raporlama kültürünün geliştirilmesi iş kazalarının azaltılmasına katkı sağlayacağ öngörülmektedir. Ayrıca İSG çalışmalarının istenilen seviye uygulanması işletmelerde pozitif bir güvenlik kültürünün oluşturulmasına ve bunları tüm çalışanlara aktarılmasına katkı sağlayacağı düşünülmektedir.

\section{Kaynakça}

Akdeniz, B. (2018). Örgüt kültürü ile güvenlik kültürü ilişkisinin iş sağlığı ve güvenliği açısından incelenmesi: Bir maden işletmesinde uygulama. Yayınlanmamış Doktora Tezi. 
Dumlupınar Üniversitesi Sosyal Bilimler Enstitüsü, Kütahya.

Akkoyun, M. (2013). Gıda sektöründe yer alan işyerlerinde iş sağlığı güvenliği uygulamaları. Çalışma ve Sosyal Güvenlik Bakanlığı İş Teftiş Kurulu Başkanlığı, Bursa.

American Nurses Association. (2016). Culture of safety. https://www.nursingworld.org/practice-policy/workenvironment/health-safety/culture-ofsafety/_(Erişim Tarihi: 16.10.2021).

Aytaç, S. (2011). İş kazalarını önlemede güvenlik kültürünün önemi. Türk Metal Dergisi, 36-39.

Büyüköztürk, Ş. (2010). Sosyal bilimler için veri analizi el kitabı (12. bask1). Ankara: Pegem Akademi.

Can, M. ve Hüseyinli, N. (2017). Çalışma hayatında iş sağlığı ve güvenliği kültürü ve otel çalışanlarının güvenli davranışlarının incelenmesi. Atatürk Üniversitesi Sosyal Bilimler Enstitüsü Dergisi, 21(4), 1397-1420.

Choudhry, R. M., Fang, D. \& Mohamed, S. (2007). The nature of safety culture: A survey of the state of the art. Safety Science, 45, 993-1012.

Clarke, S. (1999). Perceptions of organizational safety implications for the development of safety culture. Journal of Organizational Behavior, 20, 185-198.

Converse, J. M. (1987). Survey research in the United States: Roots and emergence. 1890-1960.

Cooper, M. D. (2000). Towards a model of safety culture. Safety Science, 36, 111-136.

Cox, S. J. \& Cheyne, A. J. T. (2000). Assessing safety culture in offshore environments. Safety Science, 34, 111-119.

Çelik, E. (2014). Güvenlik kültürünün güvenlik performansına etkisi: İş tatmininin aracılık rolü. Yayınlanmamış Doktora Tezi. Gazi Üniversitesi Sosyal Bilimler Enstitüsü, Ankara.

Dursun, S. (2011). Güvenlik kültürünün güvenlik performans1 üzerine etkisine yönelik bir uygulama. Yayınlanmamış Doktora Tezi. Bursa Uludağ Üniversitesi Sosyal Bilimler Enstitüsü, Bursa.

Dursun, S. (2013). İş güvenliği kültürünün çalışanların güvenli davranışları üzerine etkisi. Sosyal Güvenlik Dergisi, 3(2), 61-75.

Fraenkel, J. R. \& Wallen, N. E. (2006). How to design and evaluate research in education. New York: Mc Graw-Hill.

Fung, I. W. H., Tam, C. M., Tung, C. F. K. \& Man, A. S. K. (2005). Safety cultural divergences among management, supervisory and worker groups in Hong Kong construction industry. International Journal of Project Management, 23, 504-512.

Griffin M. A. \& Neal, A. (2000). Perceptions of safety at work: A framework for linking safety climate to safety performance, knowledge, and motivation. Journal of Occupational Health Psychology, 5, 347-358.

George, D. \& Mallery, M. (2010). SPSS for windows step by step: A simple guide and reference $\left(10^{\text {nd }}\right.$ ed.). Boston: Pearson.

Goh, Y. M., Love, P., Stagbouer G. \& Annesley, C. (2012). Dynamics of safety performance and culture: A group model building approach. Accident Analysis and Prevention, 48, 118-125.

Hair, J. F., Black, W. C., Babin, B. J., Anderson, R. E. \& Tatham, R. L. (2013). Multivariate data analysis. Pearson Education Limited.

Hasanhanoğlu, C. (2020). Güvenli işyeri yaratılmasında insan kaynakları yönetiminin önemi ve işletme verimliliği açısından iş sağlığı ve güvenliği faaliyetlerine ekonomik katkısı. Uluslararası Ekonomi ve Siyaset Bilimleri Akademik Araştırmalar Dergisi, 3(9), 2-17.

Havold, J. I. \& Nesset, E. (2009). From safety culture to safety orientation: Validation and simplification of a safety orientation scale using a sample of seafarers working for Norwegian ship owners. Safety Science, 47, 305-326.

İşçi Sağlığı ve İş Güvenliği Raporu. (2015). https://mmo.org.tr/sites/default/files/gonderi_dosya ekleri/c819fd7f01dd438_ek_0.pdf (Erişim Tarihi: 16.10.2021).

İş Sağlığı ve Güvenliği Kanunu. (2012). T.C. Resmî Gazete. 30 Haziran 2012/28339.

İş Güvenliği Uzmanlarının Görev, Yetki, Sorumluluk ve Eğitimleri Hakkında Yönetmelik. (2012). T.C. Resmî Gazete. 29 Aralık 2012/28512.

Kao, C. S., Lai, W. H., Chuang, T. F. \& Lee, J. C. (2008). Safety culture factors, group differences and risk perception in five petrochemical plants. Process Safety Progress, 27(2), 145152.

Karasar, N. (2009). Bilimsel araştırma yöntemi. Ankara: Nobel Yayıncılık.

Kim, K. D. \& Park, S. (2021). An analysis of the effects of occupational accidents on corporate management performance. Safety Science, 138, 1-8.

Lee, T. (1998). Assessment of safety culture at a nuclear reprocessing plant. Work and Stress, 12, 217-237.

Lin, S. H., Tang, W. J., Miao, J. Y., Wang, Z. M. \& Wang, P. X. (2008). Safety climate measurement at workplace in china: A validity and reliability assessment. Safety Science, 46, 1037-1046.

Martin, N. T. (2007). Safety culture assessment in campus recreational sports: item development, validity, evidence development, and reliability analyses. https://www.proquest.com/docview/304840280?pq-

origsite $=$ gscholar $\&$ fromopenview $=$ true $\quad$ (Erişim Tarihi: 16.10.2021).

Molenaar, K. R. \& Park, J. S. (2009). Framework for measuring corporate safety culture and its impact on construction safety performance. Journal of Construction Engineering and Management, 488- 496.

Muniz, B. F., Peon, J. M. M. \& Ordas, C. J. V. (2007). Safety culture: Analysis of the causal relationships between its key dimensions. Journal of Safety Research, 38, 627-641.

Neal, A., Griffin, M. A. \& Hart, P. M. (2000). The impact of organizational climate on safety climate and individual behavior. Safety Science, 34, 99-109.

Nunnally, J. C. (1978). Psychometric theory. New York: McGraw-Hill.

Oral, Y. ve Ünal T.A. (2020). 2016-2018 yılları arasında seyahat sektörüne ait iş kazası verilerinin değerlendirilmesi. OHS Academy, 3(2), 61-72.

Özkan, Y. ve Arpat, B. (2015). Mavi yakalılarda güvenlik kültürü algısı: Denizli ili kablo imalat endüstrisi örneği. Siyaset, Ekonomi ve Yönetim Araştırmaları Dergisi. 16. Çalışma Ekonomisi ve Endüstri İlişkileri Kongresi Özel Sayis1.

Parlak, T., Barışık, T. ve Yalçın, F. (2020). Gıda ürünleri imalatında çalışan personellerin iş sağlığı ve güvenliği hakkındaki farkındalık durumlarının tespiti üzerine bir araştırma. OHS Academy, 3(1), 13-27.

Smith, A. P. \& Wadsworth, E. J. K. (2009). Safety culture, advice and performance. http://www.behavioural- 
safety.com/articles/cardiff_safety_culture_report.pdf (Erişim Tarihi: 16.10.2021).

Sosyal Güvenlik Kurumu. (2020). Sosyal güvenlik kurumu 2020 istatistik

y1llıkları. http://www.sgk.gov.tr/wps/portal/sgk/tr/kurumsal/istatistik/s gk_istatistik_yilliklari (Erişim Tarihi: 15.10.2021).

Şencan, H. (2005). Sosyal ve davranışsal ölçümlerde güvenirlik ve geçerlilik. Ankara: Seçkin Yayıncılık.

Tabachnick, B. G. \& Fidell, L. S. (2013). Using multivariate statistics ( $6^{\text {nd }}$ edition). London: Pearson Education.

Tomas, J. M., Melia, J. L. \& Oliver, A. (1999). A crossvalidation of a structural equation model of accidents: Organizational and psychological variables as predictors of work safety. Work \& Stress, 13(1), 49-58

Turan Yıldız, A. (2019). Çimento fabrikalarında iş kazaları ve meslek hastalıklarının iş yeri güvenlik kültürü ile ilişsisi: MEDCEM madencilik çimento fabrikası örneği. Yayınlanmamış Yüksek Lisans Tezi. Tarsus Üniversitesi Lisansüstü Eğitim Enstitüsü, Mersin.

Yılmaz, S. ve Yılmaz, M. (2017). Türk inşaat sektöründe çalışanların güvenlik kültürü düzeyinin ve güvenlik performansı ile ilişkisinin incelenmesi. Politeknik Dergisi, 20(1), 137-149.

Zohar, D. (2010). Thirty years of safety climate research: Reflections and future directions. Accident Analysis \& Prevention, 42(5), 1517-1522. 